\title{
Darbeli Laser-Malzeme Etkileşimi Sırasında Malzemedeki Sıcaklık Dağılımının Yarı Kinetik Teori ile Analizi
}

\author{
Yıldız KOÇ* (D), Ertuğrul BALTACIOĞLU \\ İskenderun Teknik Üniversitesi, Mühendislik ve Doğa Bilimleri Fakültesi, Makine Mühendisli Bölümü, \\ İskenderun/Hatay, Türkiye
}

Geliş / Received: 18/09/2019, Kabul / Accepted: 11/07/2019

\section{$\ddot{\mathbf{O} z}$}

Günümüzde teknolojinin gelişimi ile imalat sanayisinde laserin kullanımı, düşük maliyet ve yüksek hassasiyetten dolayı önem kazanmaktadır. Laser-metal etkileşimi sırasında malzemeye olan 1sı transferi ve sıcaklık dağılımı metal şekillendirmede büyük bir önem arz etmektedir. Bu çalışmada $1.10^{10} \mathrm{~W} / \mathrm{m}^{2}$ ve $5.10^{10}$ $\mathrm{W} / \mathrm{m}^{2}$ gücündeki darbeli laser ile dört farklı malzemenin (çelik, nikel, tantal ve titanyum) etkileşimi sırasında malzeme yüzeyinde ve malzeme içerisindeki sıcaklık dağılımı zamana bağlı olarak incelenmiştir. Laser-metal etkileşimi sırasında, birinci aşamada ısı iletimi esas alınmış ve buna bağlı olarak elektron kinetik teori modeli ile malzeme ergime sıcaklığına ulaşana kadar çözüm yapılmıştır. İkinci aşamada malzeme ergime sıcaklığına ulaştıktan sonra taşınımla olan 1S1 transferi klasik metotla ve iletimle olan 1S1 transferi kinetik teori yaklaşımıyla birlikte (yarı klasik teori) ele alınarak çözüm yapılmıştır. Malzeme içerisindeki ve yüzeyindeki sıcaklık dağılımlarının malzeme termodinamik özellikleriyle değişimini belirlemek gayesiyle dört farklı malzeme incelenmiş ve elde edilen sıcaklık dağılımları birbiriyle kıyaslanmıştır. Nümerik çözümler için bir bilgisayar programı geliştirilmiştir.

Anahtar Kelimeler: Laser-metal etkileşimi, laser ısıtma, kinetik teori, sıcaklık dağılımı

Çalışma doktora tezinden üretilmiştir.

\section{Analysis of Temperature Distribution in Materials during Pulsed Laser-Material Interaction with Semi-Kinetic Theory}

\begin{abstract}
Nowadays, with the development of technology, the use of laser in the manufacturing industry is gaining importance because of its low cost and high precision. During the laser-metal interaction, heat transfer to the material and temperature distribution on the material are of great importance in metal forming. In this study, the time depended temperature distribution on the material surface and within the material were examined for interaction of the $1.1010 \mathrm{~W} / \mathrm{m}^{2}$ and $5.1010 \mathrm{~W} / \mathrm{m}^{2}$ power pulsed lasers with four different materials (steel, nickel, tantalum and titanyum). During laser-metal interaction, in the first step, heat transfer was considered and the analysis was made until the material reaches melting temperature with electron kinetic theory model. In the second step, after the material reached melting temperature, heat transfer by convection was analysed by classical method and heat transfer by conduction was analysed by heat transfer kinetic theory approach (semi-classical theory). In order to determine the variation of temperature distributions within material and material surface depending on material thermodynamic properties, four different materials were examined and the obtained temperature distributions were compared with each other. A computer program was developed for numerical solutions.
\end{abstract}

Keywords: Laser-metal interaction, laser heating, kinetic theory, temperature distribution 


\section{Giriş}

LASER sözcüğ̈̈; Uyarılmış ışıma yayınımı ile 1şı ğın şiddetlendirilmesi anlamına gelen " Light Amplification by Stimulated Emission of Radiation" sözcüklerinin baş harflerinden oluşmaktadır (Joe vd., 2017). Laser yaklaşık elli y1llık çalışma ve araştırma sonucunda ancak 1960 yılında ortaya konulabilmiştir. Günümüzde teknolojinin gelişmesiyle birlikte sanayi, savunma, tıp, mühendislik ve haberleşme gibi birçok alanda kullanılmaktadır (Beck vd., 2010; Remo ve Adams, 2008; Koç vd., 2018). Yayılan dalga boyları mor ötesi veya kızıl ötesi bölgede ise bu tür dalgaları yayan veya üreten kaynaklara da laser denir. Townes ve Schawlow (1958) tarafindan teorik olarak laserin meydana gelebileceği İlk olarak 1958 yılında ortaya atıld1. Maiman (1960), bu teori ile ilk yakut laseri 1960 yılında geliştirerek, Ruby kristalinden laser 1şını üreterek ilk darbeli katı laser meydana getirilmiş oldu. $\mathrm{Bu}$ buluştan sonra Laser üzerine yapılan çalışmalarda araştırmacılar tarafindan, kullanım alanlarına göre çok çeşitli laserler geliştirilmiştir.

Laserler, metal işleme endüstrisinde yaygıın olarak kullanılmaktadır. Çünkü işlenmesi zor malzemeler için uygun bir üretim yöntemi sağlar ve mikro işleme gibi özel uygulamaları içerir. Laserler, hassas ve düşük maliyetleri nedeniyle çeşitli malzemelerin kesilmesi, delinmesi, kaynaklanması ve isıl işleminde yaygın olarak kullanılmaktadır. Darbeli laser ile malzemenin 1sitmasında, malzemenin sıcaklığındaki artış, yalnızca malzemenin termal ve mekanik özelliklerine değil, aynı zamanda optik özelliklerine de önemli ölçüde bağlıdır. Darbeli Laserle malzemenin 1sıtılması işleminde; erime, buharlaşma ve plazma oluşumu meydana gelebilmektedir (Koç, 2004)

Iş1k ve manyetik dalgaların iletilmesini sağlayan foton parçacıkları olup lazer ışını ile metal etkileşimi sırasında fotonlar malzemeye çarptığında yüzeydeki $0.1 \mu \mathrm{m}$ derinlikteki elektronlar tarafindan emilen foton enerji ile uyarılan elektronlar temel enerji seviyesinden, üst enerji seviyelerine çıkarlar. Üst enerji seviyesine çıkan ve kararsiz halde bulunan elektronlar tekrar temel enerji seviyesine inerken sahip oldukları enerjileri ile fonon salınımı yaparlar. Fonun enerjisi ile uyarılan malzeme içerisindeki diğer elektronlar yine temel seviyeden üst enerji seviyelerine çıkar ve tekrar temel seviyeye düşerken fonun salımı yaparlar. Katı malzeme içerisindeki 1s1 iletimi radyasyon (foton) ile değil fononlar ile katı malzeme içerisinde iletilir. Fononlar; Fiziksel olarak bir parçacık olmadığı için genellikle paçacığımsı olarak adlandırılırlar. Optik ve akustik fonon olmak üzere iki çeşidi bulunur. Optik fononların enerjileri daha yüksektir. Akustik fononlar ise daha düşük enerjilidir. Katı malzeme içerisindeki 1s1 iletimi optik fononlar ile ses iletimi ise akustik fononlar ile iletilir.

Yılbaș vd. (1990) yaptıkları çalıșmada, lasermetal etkileşimi sırasında malzemedeki absorpsiyon mekanizmasını incelemişlerdir Qin ve Tien (1992) metallerin kisa darbeli laserle 1sıtılması için iki aşamalı bir 1sı iletimi modeli ortaya koydu. Enerji denkleminin çözümünde, elektronun termik gevşeme işleminin hızı için bir elektron - fonon birleştirme faktörü ele alındı.

Yılbaş (1993) yaptığı çalışmada, zamana bağlı yoğunluğu değişen darbeli laser ile 
malzemenin 1sitılması sonucu sicaklik dağılımlarını Laplace dönüşümleri ve integral bir yöntem kullanılarak elde etmiştir. Bazı araştırmacılar, laser ve katı malzeme etkileşimini Fourier 1s1 iletimi teorisi modellemişlerdir. Neto ve Lima (1994) tarafindan üç boyutlu sicaklık prodüksiyonlarını öngören lineer olmayan bir model araştırıldı. Oluşturdukları model, kullanım için geliştirilen doğrusal olmayan parabolik diferansiyel denklemlere dayanıyordu Literatürde, katılarda laser malzeme etkileşimi nedeniyle sıcaklığın dağılımını Fourier denklemi kullanılarak modellenmesine yardımcı olan birçok çalışma vardır. Koç (1995), $1.10^{10} \mathrm{~W} / \mathrm{m}^{2}$ ve $5.10^{10} \mathrm{~W} / \mathrm{m}^{2}$ laser işleme gücü için ortaya çıkan 1sı transferini araştırdı. Aynı zamanda 1S1 iletimi ve taşınımını, sıcaklık dağılımını belirlemek için farklı metal türlerinde elektron kinetik teorisini kullanarak analiz yaptı. Laser metal, iletim Laser 1şını, laser 1şını malzeme yüzeyine çarptığında, fotonların bir kısmı iletken banttaki elektronlar tarafindan absorbe edilir. Laser 1şını içindeki foton enerjisi elektronlara aktarılır. Bunun bir sonucu olarak, yüzey elektronlarının kinetik enerjisi artar. Laser 1şından absorpsiyon yoluyla enerji kazanan elektronlar, kafes molekülleri ile arka arkaya çarpışmalar yapar ve kafes fononlarını daha yüksek enerjilere yönlendirir. Böylece, moleküller artan titreşim enerjilerine, yani sonunda daha yüksek sicaklıklara sahip olurlar. Laser yüzey işlemlerinde yüzeyde buharlaşan malzemenin ayrılma hızı, malzemenin sıcaklığına bağlı olduğundan, doğru bir şekilde hesaplanması çok önemlidir Fourier iletim denkleminin sicaklık dağılımını daha yüksek yoğunluklarda belirlemek için kullanılması, teoride sınır koşullarında yapılan varsayımlar nedeniyle önemli hatalara neden olur. Fourier iletim denklemi teorisi, belirli bir düzlem boyunca
1S1 akıs1, düzlemdeki sıcaklık gradyanının bir fonksiyonudur (Koç vd. 1998; Smon vd. 1993). Laser işleme mekanizmasının analizinde, merkezi özellik, Fourier iletim denkleminin, laser 1şından gelen foton enerjisinin hedef malzemenin moleküler kafesine aktarılma şeklini açıklamak için kullanılmıştır. Laser-malzeme etkileşim sürecini belirleyen bu enerji transfer mekanizmasıdır. Fourier iletim denkleminin sadece katı sınırlar içinde geçerli olduğu ve malzemeleri 1şınlayan kısa laser darbeleriyle oluşan bir 1sı transfer işleminin analizinde geçersiz olduğu araştırmacilar tarafindan gösterilmiştir (Koç 1995). Yilbas ve Sami (1995), darbeli laserli 1sıtma işlemi için bir elektron kinetik teori yaklaşımı getirmiştir. İletim mekanizması, art arda gelen elektron ve fonon çarpışmalarıyla değerlendirildi. Prensip olarak, laserle işleme, laser işından gelen 1şınlanan enerji ile iş parçasına ve iş parçasına iletim ve konveksiyon 1sıs1 arasındaki enerji dengesi ile yönetilebileceğini belirtmişlerdir Böylece, katıların laserle 1sıtılması için daha alakalı bir teori, yani elektron kinetik bir teori, bazı araştırmacılar tarafından geliştirilmiştir. Laser radyasyonunun absorpsiyon derinliği, atomlar arası boşluklarla karşılaştırılabilen ortalama-serbest elektron yoluna bağlıdır, bu nedenle, bu problemi incelemek için gereken mesafeler ölçeğinde malzemenin artık homojen bir süreklilik olarak kabul edilemez. Belirli bir düzlem boyunca 1s1 akması malzeme boyunca elektron enerji dağılımına bağlıdır (Yılbaş ve Şahin,1993; Yılbaş, 1997; Yılbaş ve Koç, 1986)

Yukarıdaki tartışmaların 1şı̆̆ında, laserli malzeme etkileşimi ile malzemenin 1sıtma sırasındaki sıcaklık dağılımını incelemek için yeni bir modele ihtiyaç vardır. Kinetik teori yaklaşımını; problemi incelemede temel, elektron fonon çarpışmalarıyla enerjinin 
taşınmasını tanımlamaktadır. Sonuç olarak, bu çalışma, darbeli laserli ısıtma işleminde iletim için uygun bir kinetik teori yaklaşımı ve taşınım için ise klasik metot kullanılarak malzeme içerisindeki sıcaklık dağılım analizleri yapılmıştır. İki farklı güçteki darbeli laser ile malzemenin isıtılması işlemi sırasında sıcaklık artışı sayısal olarak hesaplanmıştır. Dört farklı malzemenin (Demir, Nikel, Titanyum ve Tantal) darbeli laser ile 1sitılmasi sonucu malzemedeki 1s1 iletimi kinetik teori ile ve 1sı taşınım klasik metotla çözümü sonucu malzemedeki malzeme yüzeyinde ve malzeme içerisindeki sıcaklık dağılımlarının zamana göre dağılımı verilmiştir.

\section{Materyal ve Metot}

\subsection{Sistemin tanıtımı ve kabuller}

Laser malzeme etkileşimi sırasında malzemenin ergitilmesi uygulamalarında Fourier iletim denklemine bağlı sınırlamalar nedeniyle yeni bir modele ihtiyaç vardır. Temelde problemin çözümü için enerjinin elektronlar ile taşınmasını tanımlamak için kinetik teori kullanılır (Yılbaş, 1986). Bu model şu şekilde açıklanabilir. Dışardan malzeme yüzeyine uygulanan elektromanyetik 1şıma, metallerin iletim bandinda bulunan serbest elektronlar tarafindan absorbe edilirler. Enerjisi artan bu elektronlar atomlarla çarpışarak enerjilerinin bir kısmını atomlara terk ederler. $\mathrm{Bu}$ etkileşimden dolayı atomların foton enerjileri artar ve çevresinde bulunana atomları da titreşime zorlayarak fonon enerjilerinin artmasına sebep olur. Problemin çözülmesine kolaylık getirmesi için bazı kabuller yapılmıştır. $\mathrm{Bu}$ çalışmada termoiyonik emisyondan dolayı enerji kaybı ihmal edilmiştir. Enerji transfer işlemi elektron- foton çarpışmaları sırasında meydana gelmektedir. Çarpışmalardan sonra elektronların yönleri hemen değişir, fakat elektron akısı herhangi bir yönde sabit kalır. Çarpışma esnasında fazla elektron enerjisinin küçük bir oranı fotonlara geçer. Çözümde lokal dengede olduğu, $\mathrm{t}=0$ 'da anında malzeme üniform bir sicaklıkta olduğu kabulü yapılmaktadır. Plazmanın sürekli bir rejim gösterdiği, çekirdekleşme ve sıvı metal fışkırtma mekanizmasının olmadığı, laser optik sisteminden ve plazmadan dolayı laser 1şınının fiziksel değişiminin ihmal edilmektedir. Elektronların, ortalama serbest yolunun sicaklık değişimlerinden etkilenmeyeceği olarak siralanabilir. Katı laserlerden, laser 1şının çıkışı yoğunluğu birkaç mikrosaniye de $(\mu \mathrm{s})$ maksimum değere ulaşır. Yaklaşık 10 mikrosaniye sonra tekrar düşer. Darbeli laserin güç yoğunluğunun zamana göre dağılımı Şekil 1 'de verilmiştir (Koç, 1995).

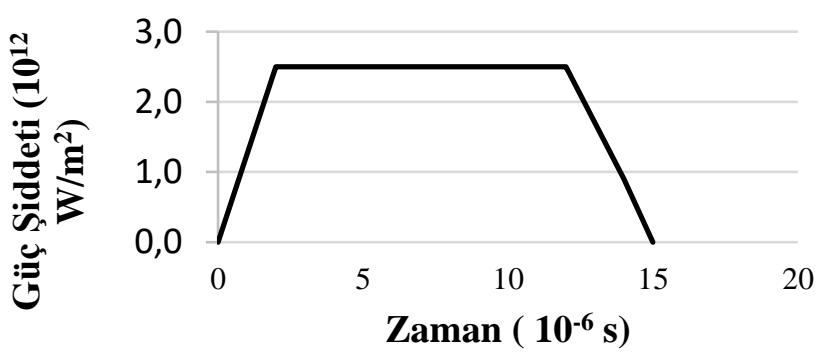

Şekil 1. Darbeli laserin güç yoğunluğunun zamana göre dağılımı

$\mathrm{Bu}$ çalışmada, darbeli laser ve malzeme etkileşimi sonucu yarı kinetik teori (1S1 iletimi kinetik teori ile ve 1 sı taşınım klasik metotla) ile sıcaklık dağılımları incelenecek olan malzemelerin fiziksel özellikleri Tablo 1 'verilmiştir. 
Tablo 1. Malzemelerin fiziksel özelikleri (Koç, 1995).

\begin{tabular}{|l|l|r|r|r|r||}
\hline Malzeme Özelliği & Birimi & Çelik & Nikel & Tantal & Titanyum \\
Erime Sıcaklığ 1 & ${ }^{\circ} \mathrm{C}$ & 1473 & 1728 & 3270 & 1950 \\
Kaynama sıcaklığ1 & ${ }^{\circ} \mathrm{C}$ & 3100 & 3110 & 5700 & 3350 \\
Kritik sıcaklığ & ${ }^{\circ} \mathrm{C}$ & 10300 & 10800 & 22000 & 12500 \\
Özgül 1sıs1 & $\mathrm{J} / \mathrm{kg} . \mathrm{K}$ & 460 & 447 & 150 & 523 \\
Isıl iletkenlik & $\mathrm{j} / \mathrm{s} . \mathrm{m} . \mathrm{K}$ & 80,3 & 90.3 & 57.7 & 20,4 \\
Yoğunluk & $\mathrm{kg} / \mathrm{m}^{3}$ & 7880 & 8900 & 16620 & 4570 \\
Soğurma katsayısı & $1 / \mathrm{m}$ & $6.16^{*} 10^{7}$ & $6.75^{*} 10^{7}$ & $5.69^{*} 10^{7}$ & $4.38^{*} 10^{7}$ \\
Isıl difüzivite & $\mathrm{m}^{2} / \mathrm{sn}$ & $0.227^{*} 10^{-4}$ & $0.229^{*} 10^{-4}$ & $0.247^{*} 10^{-4}$ & $0.092^{*} 10^{-4}$ \\
\hline
\end{tabular}

Kinetik teoriye göre; malzeme içerisindeki serbest elektron modeli göz önüne alınarak 1S1 iletiminin incelenmesi gerekir. Serbest elektronlar, yüzey içerisinde belirli bir hıza sahip olan ve serbest olarak hareket eden elektronlardır. Belirli bir yüzeyle sınırlandırılan hacim içerisinde bulunan elektronların enerjileri, fermi dağılım yasasına göre değişirler. Moleküler kafese içerisindeki elektronlar, titreşim hareketlerine bağlı olarak fonon enerjisine sahip olurlar (Merhav, 2018). Bir kafes atomunun titreşimi göz önüne alındığında, bir bağlı elektronun "s" kafes alanındaki (Şekil 1) yer değiştirmesi şöyle ifade edilebilir (Koç, 1995).:

$$
A_{g} \cdot e^{i(g s-\omega g t)}
$$

Ag, hareketin genliğidir. Kafes titreşim enerjisi frekansa $(\omega)$ ve ortalama fonon sayısına (n) bağlıdır. T sicaklığında, termal dengedeki fonon sayısı aşağıdaki Planck dağılımının bir fonksiyonunu olarak yazabilir (Dekker, 1958): veya

$n+\frac{1}{2}=\frac{1}{2} c . n t h \cdot \frac{\hbar \omega}{2 k_{B} T}$

Burada; $\mathrm{k}_{\mathrm{B}}$ : Boltzman sabitidir, c: 1 şık hızıdır, n; fonon sayısı ve nth: Kuantum durumunda bulunan uyarma sayısıdır. Planck dağılımında, ısıl dengede bulunan aynı harmonik salınımların değişimi göz önüne alınır (Kittel 2005). Kuantum durumunda bulunan "nth" daki uyarma sayısının, kuantum durundaki " $(\mathrm{n}+1)$ th" salınımlarının sayısına oranı Boltzman sabitine bağlı olarak;

$$
\mathrm{N}_{\mathrm{n}+1} / \mathrm{N}_{\mathrm{n}}=\mathrm{e}^{\hbar \omega / \mathrm{k}_{\mathrm{B}} \mathrm{T}}
$$

Şeklinde yazılır. N; atom sayısıdır. $\mathrm{Bu}$ durumda "nth" kuantum durumundaki salınımların toplam sayısına oranı;

$$
\frac{N_{n}}{\sum_{s=0}^{\infty} N_{s}}=\frac{e^{-n \hbar \omega / k_{B} T}}{\sum_{s=0}^{\infty} e^{-s \hbar \omega / k_{B} T}}
$$

Salınımın ortalama uyarma kuantum sayısının düzenlenmesi yapılırsa ve $x=\exp (-$ $\left.\hbar \omega / k_{B} T\right)$ ise, aşağıdaki formu alır; 


$$
\sum_{s} s . e^{s}=x \frac{d}{d x} \sum_{s} x^{s}=\frac{x}{(1-x)^{2}}
$$

şeklini alır. Klasik anlamda, her salınımın $\hbar \omega$ $\approx \mathrm{k}_{\mathrm{B}} \mathrm{T}$ " enerjisine sahip olduğu kabul edilir. $\omega$ frekansındaki salınımın ortalama enerjisi $\mathrm{h}=\hbar \omega$ 'dır. Bir atom titreşimi için ortalama enerji;

$$
\mathrm{E}=\mathrm{h} . \omega \mathrm{g} /[\exp (\mathrm{h} \cdot \omega \mathrm{g} / \mathrm{k} \cdot \mathrm{T}-1)]
$$

Şeklinde yazılır. Salınımların ısıl kapasitesi;

$$
C_{v}=\left(\frac{d E}{d T}\right)_{v}=N \cdot k_{B} \cdot\left(\frac{\hbar \cdot \omega}{\tau}\right)^{2} \cdot \frac{e^{\hbar \omega / \tau}}{\left(e^{-\hbar \omega / \tau}-1\right)^{2}}
$$

Şeklinde yazılır. $\quad \mathrm{C}_{\mathrm{v}}$; salınımın 1 sil kapasitesidir. Üç boyutlu $\mathrm{N}$ adet atomun salınımları için denkleme " $3 \mathrm{~N}$ ” yazılır. Çünkü her bir atomun üç serbestlik derecesine sahiptir. Kafes titreşimlerinden dolayı tek bir yöndeki $\mathrm{N}$ adet molekülün enerjisi;

$$
E_{x}=N_{x} \cdot k_{B} \cdot T
$$

$\mathrm{Bu}$ denklemde $\mathrm{E}_{\mathrm{x}}$; foton enerjisi olarak tanımlanabilir. Genel olarak homojen yapıdaki bir malzemede, sürekli halde 1s1 geçişi olduğu kabulü ile 1sıl iletkenlik katsayısı tanımlanmış olup tek yöndeki 1sıl iletkenlik katsayısı aşağıdaki bağıntıyla tanımlanmıştır (Yılbaş ve Kalyon, 2002; Koç 1995)

$$
\mathrm{k}=\frac{\mathrm{N} \cdot \overline{\mathrm{V}}_{\mathrm{x}} \cdot \mathrm{k}_{\mathrm{B}} \cdot \lambda}{6}
$$

Burada; $\lambda$ : elektronların serbest yolu ve $\bar{V}$ : serbest molekülün bağıl hızı olup, Deby sıcaklığından daha yüksek sıcaklar için, ısıl iletkenlik sabit olacaktır. Analizde, yüzeyden yansıyan elektronlardan dolayı bir zorluk meydana gelmektedir. Bu güçlük Şekil 2.a'de görüldüğü gibi yüzeyde bir yansıtıcının olduğu kabulüyle aşılmıştır. Bu analizde, malzemede hareket eden ve yüzeyden geri yansıyan elektronların matematiksel açıklamaları verilmiştir. Bu durum, yüzeye yerleştirilmiş hayali ayna ile yüzeyden uzaklaştırılabilir. Bir elektronun çarpışmadan $\mathrm{x}$ mesafesine ulaşması $\mathrm{x}<<\lambda$ için $\exp (\mathrm{x} / \lambda)$ olur. Bir elektron $\mathrm{dx}$ aralığının sonunda çarpışma olasılığ $1 \mathrm{dx} / \lambda$ olarak verilir. Şekil 2.b'ye göre, II, III, I için son çarpışma olasılığı, dx mesafesindeki elektronların yolları aşağıdaki gibidir. 


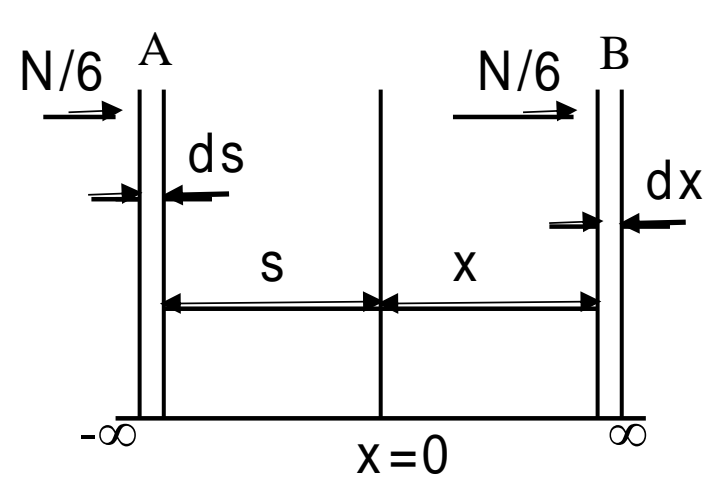

a) Elektron akış1

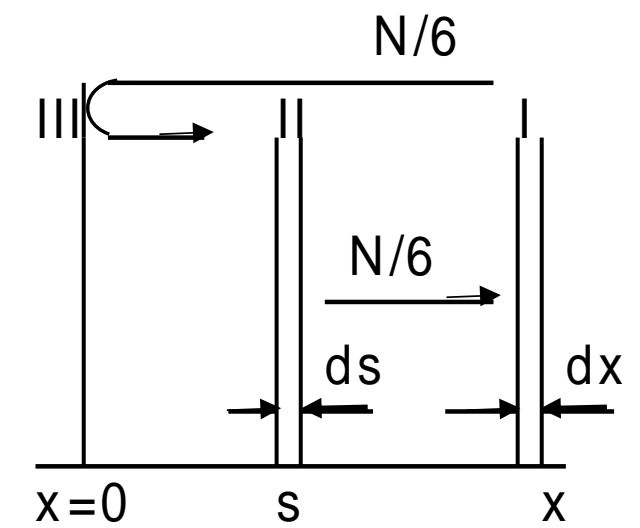

b) Hayali ayna kabulü

Şekil 2. Elektronların enerji taşınımı ile ilgili hareket yönü

Elektronlar, Şekil 2'de görülen II, I veya III, I yolunu izlerler. Yüzey bölgesinde elektronların toplam çarpışma ihtimali aşağıdaki gibi yazılabilir (Koç, 1995).

$$
\int_{-\infty}^{\infty} \exp \left[-\frac{|x-s|}{\lambda}\right] \frac{d s}{\lambda} \cdot \frac{d x}{\lambda}
$$

İntegralin negatif sınırı, yüzeyden yansıyan elektronlar ve düşünülen yansitıcıdan dolayıdır. Bütün cisimde elektron-foton çarpışması esnasında net enerji transferi aşağıdaki gibidir.

$$
\begin{aligned}
& \Delta E_{x, t}=\int_{-\infty}^{\infty} \exp \left[-\frac{|x-s|}{\lambda}\right] \frac{d s}{\lambda} \cdot \frac{d x}{\lambda} . f . \\
& \left(E_{s, t}-E_{x, t}\right)
\end{aligned}
$$

Burada; $E_{\mathrm{s}, \mathrm{t}}$ ve $\mathrm{E}_{\mathrm{x}, \mathrm{t}}$ dizileri sirasiyla bir noktadaki elektronların ve atomların enerjileridir. f parametresi, atomun çarpışma sırasında elektronun fonona verdiği enerji yüzdesidir ve $\mathrm{f}=10^{-4}$ olarak alınır (Dekker, 1981; Yan vd., 2007). Isı geçişinde, x uzaklık formülü olan homojen bir ortamdan geçiş, aşağıdaki denklem ile yazılır.

$$
\frac{d l}{d x}=-\delta .1(x)
$$

Burada $\delta$ soğurma katsayısıdır. Buradaki negatif işaret $\delta$ pozitif büyüklüğü ile soğurmadan dolayı 1şın şiddetindeki azalmayı belirtmektedir. $\mathrm{Bu}$ denklem integre edersek

$I=I_{0} \cdot \exp (-\delta \cdot x)$

Burada; Io gelen laser ışınının maksimum şiddetidir. Bundan dolayı, laser ışınının şiddeti için yukardaki formül kullanılarak, dt zaman alanında $\mathrm{dx}$ boyunda uygulanan enerji aşağıdaki gibi yazılabilir;

$$
\Delta \mathrm{E}_{\mathrm{x}, \mathrm{t}} \underset{\mathrm{abs}}{\mid}=\mathrm{I}_{0} \cdot \delta \cdot \mathrm{e}^{-\delta \cdot \mathrm{x}} \cdot \mathrm{A} \cdot \mathrm{dt} \cdot \mathrm{dx}
$$

dt zamanında $\mathrm{dx}$ boyundaki metalde ki toplam enerji artışı;

$$
\text { N.A. }\left(E_{x, t}+d t-E_{x, t}\right) \cdot d x=\Delta E_{x, t}+\Delta E_{x, t} \underset{a b s}{\mid}
$$

Bundan dolay1 toplam enerji transfer denklemi, 


\section{N.A. $\left(E_{x, t}+d t-E_{x, t}\right) \cdot d x=I_{0} \cdot \delta \cdot \exp (-\delta \cdot x) . A . d B . . d x a n l a ~ b i r l i k t e$ elektronlar ve moleküller $+$ arasındaki enerji transferi, elektronların ve

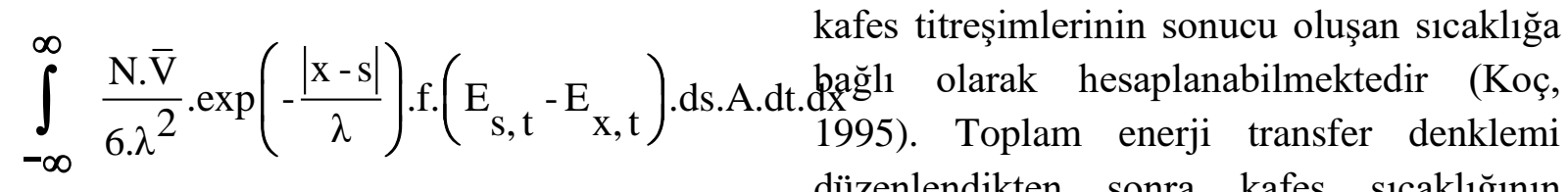 düzenlendikten sonra kafes sıcaklığının değişimi aşağıdaki şekilde yazılabilir.}

$$
\begin{aligned}
& \frac{\mathrm{dT}(\mathrm{x}, \mathrm{t})}{\mathrm{dt}}=\frac{\mathrm{I}_{0} \cdot \delta}{\rho \cdot \mathrm{Cp}} \exp (-\delta \cdot \mathrm{x})-\frac{\mathrm{K} \cdot \mathrm{f}}{2 \cdot \lambda^{3} \cdot \rho \cdot \mathrm{Cp}} \mathrm{T}(\mathrm{x}, \mathrm{t})+\frac{\mathrm{K} \cdot \mathrm{f}}{4 \cdot \lambda^{3} \cdot \rho \cdot \mathrm{Cp}}\left[\int_{0}^{\infty} \exp \left(-\frac{|\mathrm{x}+\mathrm{s}|}{\lambda}\right) \mathrm{T}(\mathrm{s}, \mathrm{t}) \cdot \mathrm{ds}\right. \\
& \left.+\int_{0}^{x} \exp \left(-\frac{|x-s|}{\lambda}\right) T(s, t) \cdot d s+\int_{x}^{\infty} \exp \left(-\frac{|x-s|}{\lambda l}\right) T(s, t) \cdot d s\right] \\
& \frac{d U}{d T}=\frac{U}{T}+\left(C p_{2}-C p_{1}\right)-\frac{U}{\left(v_{2}-v_{1}\right)}\left[\left(\frac{\partial v_{2}}{\partial T}\right)_{P}-\left(\frac{\partial v_{1}}{\partial T}\right)_{P}\right]
\end{aligned}
$$

\subsection{Klasik metotla ısı taşınımı}

Laser metal etkileşim esnasında, malzemenin katıdan sıviya ve sivadan buhara faz değişimleri esnasında önemli bir miktar da enerjiye ihtiyaç duyacaktır. $\mathrm{Bu}$ faz değişimleri sırasında iletim, buharlaşma, radyal akış ve soğurma gibi fiziki olayların meydana geldiği kabul edilir (Belforte ve Levitt 2012; Bulgan vd.,1991). Maddenin, buhar faza geçişinde bir yerde buharlaşma gizli ısısına ihtiyaç vardır. Burada buharlaşma gizli 1sısı eliptik fonksiyon sıcaklığı gibi verilir. Uygun denklem yazılırsa (Koç, 1995).

$$
U(T)=U_{0}\left[1-\left(T_{S} / T_{0}\right)^{2}\right]^{1 / 2}
$$

Burada; $\mathrm{U}_{0 \text { : }}$ mutlak sıfirda buharlaşma gizli 1sısıdır. Sabit basınçta, gizli ısının sıcaklıkla değişimi aşağıdaki gibi ifade edilir (Prokhorow, 1990).
Burada; $\mathrm{Cp}_{1}$ ve $\mathrm{Cp}_{2}$ sabit basınçta özgül 1sılar olup, $v_{1}$ ve $v_{2}$ özgül hacimlerdir. 1 ve 2 indisleri sirasıyla sıv1 ve buhar fazlarını gösteren alt indislerdir. Enerjinin dönüşüm denklemini;

Io $=\rho \mathrm{Vs}[\mathrm{U}(\mathrm{Ts})+\mathrm{Cp} \mathrm{Ts}]$

ve yüzeyin buharlaşma hızı;

$$
\mathrm{V}_{\mathrm{S}}=\left[\frac{\mathrm{k}_{\mathrm{B}} \cdot \mathrm{T}_{\mathrm{S}}}{2 \cdot \pi \cdot \mathrm{m}}\right]^{1 / 2} \cdot \exp \left[-\frac{\mathrm{U}\left(\mathrm{T}_{\mathrm{S}}\right)}{\mathrm{k}_{\mathrm{B}} \cdot \mathrm{T}_{\mathrm{S}}}\right](20)
$$

Şeklinde yazılır. Vs; yüzeydeki buharlaşma hızı ve Ts; yüzey sıcaklığı olup eşzamanlı ifadelerdir. Bunlar vakum şartlarındaki buharlaşma neticesinde standart kaynama sıcaklığının altındaki sıcaklıklar için geçerlidir (Yılbaş ve Apalak, 1987). Düşük yüzey sıcaklıklarının üzerindeki kritik nokta sıcaklığı için hız ifadesini (Yilbaş ve Yilbaş 1988); 


$$
\mathrm{V}_{\mathrm{S}}=\left[\frac{\mathrm{k}_{\mathrm{B}} \cdot \mathrm{T}_{\mathrm{S}}}{2 \cdot \pi \cdot \mathrm{m}}\right]^{1 / 2}
$$

ve laser gücüne bağlı olarakta;

$$
\mathrm{V}_{\mathrm{S}}=\left[\frac{\mathrm{I}_{0}}{\rho \cdot \mathrm{Cp} \cdot \mathrm{T}_{\mathrm{S}}}\right]
$$

şeklinde ifade etmişlerdir. Ancak bu denklemler, atmosfer şartlarında ve ergime sıcaklıklarının altında doğru sonuç vermezler. (21) ve (22) eşitliklerinden güç ifadesi çekilerek gerekli işlemler yapılırsa;

$I_{o}=\rho \cdot C p \cdot T_{S} \cdot\left[\frac{k_{B} \cdot T_{S}}{2 \cdot \pi \cdot m}\right]^{1 / 2}$

şeklinde yazılır. Yılbaş (1986) sürekli hal rejimini için gerekli analizleri yapıp, erime ve buharlaşma ifadelerini kullanarak birim hacim 1 sı transfer oranını hesap etmiştir. $\mathrm{Bu}$ 1S1 transferi oranı aşağıdaki bağıntı ile verilmiştir.

$$
\text { p.Cp. } \mathrm{V}_{\mathrm{S}} \cdot \frac{\partial \mathrm{T}}{\partial \mathrm{x}}
$$

Genel 1S1 transfer denklemini yazacak olursak, 1s1 iletimi olarak elektron kinetik teori modeliyle elde edilen denkleminden, taşınım olarak denkleminde yazılan erime ve buharlaşma ifadelerini esas alan denklemler beraberce aşağıdaki şekilde yazılabilir.

$$
\begin{aligned}
& \frac{d T(x, t)}{d t}=\frac{I_{0} \cdot \delta}{\rho \cdot C p} \exp (-\delta \cdot x) \\
& -\frac{K \cdot f}{2 \cdot \lambda^{2} \cdot \rho \cdot C p} T(x, t) \cdot+\frac{K \cdot f}{4 \cdot \lambda^{3} \cdot \rho \cdot C p} \\
& {\left[\begin{array}{l}
\int_{0}^{\infty} \exp \left(-\frac{|x+s|}{\lambda}\right) T(s, t) \cdot d s
\end{array}\right.}
\end{aligned}
$$

$$
\begin{aligned}
& +\int_{0}^{x} \exp \left(-\frac{|x-s|}{\lambda}\right) T(s, t) \cdot d s+ \\
& \left.\int_{x}^{\infty} \exp \left(-\frac{|x-s|}{\lambda}\right) T(s, t) \cdot d s\right]+\rho \cdot C p \cdot V_{S} \cdot \frac{\partial T}{\partial x}
\end{aligned}
$$

$\mathrm{Bu}$ denklem laser 1sıtma işlemleri için kinetik teoriye göre iletim ve klasik metoda göre taşınım (yarı klasik teori) etkilerini içeren sıcaklık dağılımını veren denklemdir.

\section{Bulgular}

Laser-malzeme etkileşimi sırasında, malzemede meydana gelen sıcaklık dağılımı zamana bağlı olarak tek boyutta incelenmiştir. $\mathrm{Bu}$ çalışmada laser güç şiddeti $1.10^{10} \mathrm{~W} / \mathrm{m}^{2}$ ve $5.10^{10} \mathrm{~W} / \mathrm{m}^{2}$ olan laser 1 şını ile Çelik, Nikel, Tantal ve Titanyum malzemelerinin etkileşimi esnasındaki sıcaklık dağılımlarının analizi 1sı iletimi kinetik teoriye ve $1 \mathrm{~s}$ taşınımı klasik metoda (yarı kinetik teori yaklaşımı) göre yapılarak bir bilgisayar programı hazırlanmıştır. Malzemelerin ergime sıcaklıklarına ulaşma zamanları termofiziksel özeliklerine bağlı olarak birbirinden farklı olmasindan dolay1 aynı güç yoğunluklarında her malzemenin ergime sıcaklığına ulaşma zamanı birbirinden farklıdır. Sekil 3'de $1.10^{10} \mathrm{~W} / \mathrm{m}^{2}$ ve $5.10^{10}$ $\mathrm{W} / \mathrm{m}^{2}$ güç yoğunluklarındaki laser ışını ile etkileşimi sırasında yarı klasik teori yaklaşımı ile bulunan malzeme yüzeyindeki sıcaklık dağılımının zamana göre değişimi verilmiştir. 


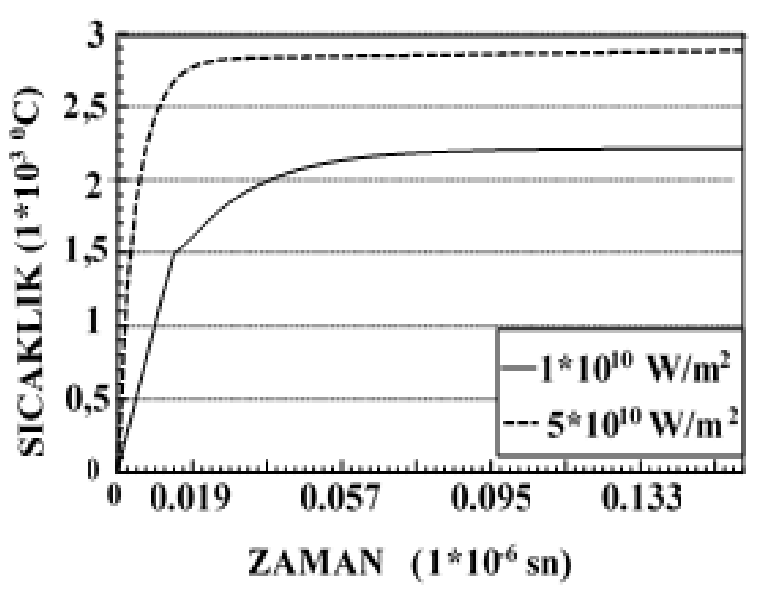

Çelik

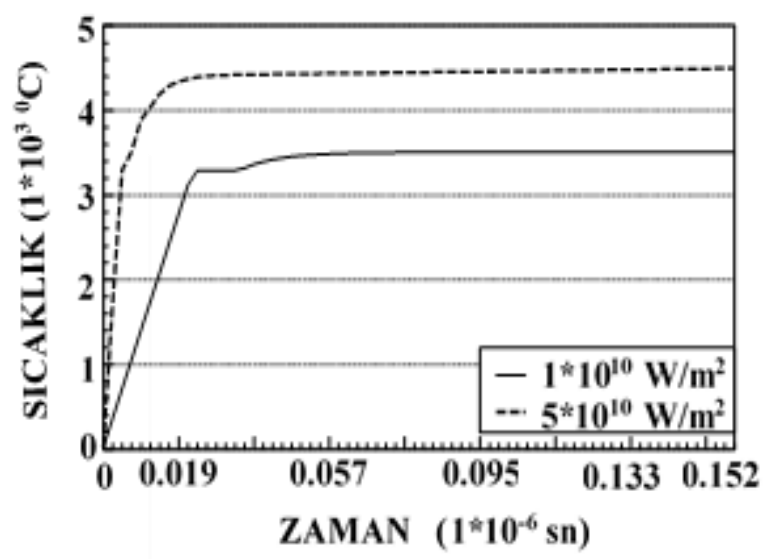

Tantalum

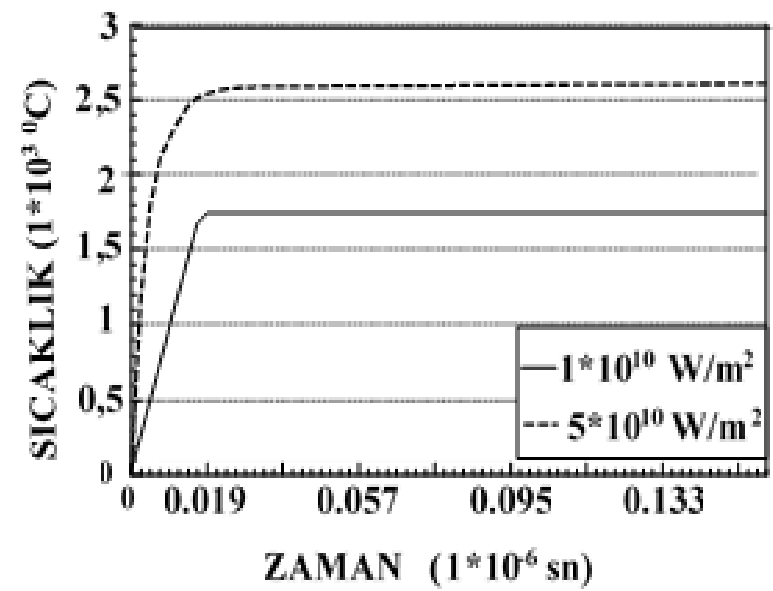

Nikel

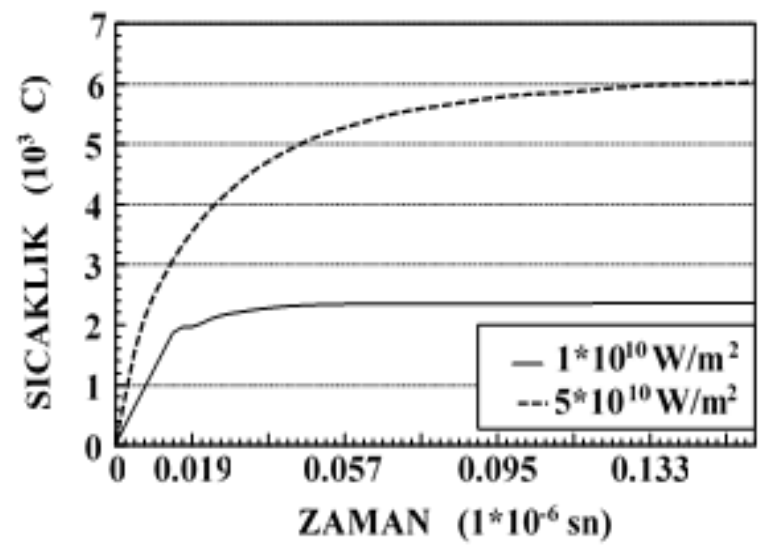

Titanium

Sekil 3. Darbeli laser $1.10^{10} \mathrm{~W} / \mathrm{m}^{2}$ ve $5.10^{10} \mathrm{~W} / \mathrm{m}^{2}$ güç yoğunluklarındaki laser 1 şını ile etkileşimi sırasında yarı klasik teori yaklaşımı ile bulunan malzeme yüzeyindeki sıcaklık dağılımının zamana göre değişimi

Şekil 3'de yarı klasik teori (1s1 iletimi kinetik teoriye ve 1s taşınımı klasik metoda) yaklaşımına göre bulunan ve darbeli laser $1.10^{10} \mathrm{~W} / \mathrm{m}^{2}$ ve $5.10^{10} \mathrm{~W} / \mathrm{m}^{2}$ güç yoğunluklarındaki laser 1şıిı ile sırasıyla Çelik, Nikel, Tantal ve Titanyum malzemelerinin etkileşimi sırasında malzeme yüzeyinde meydana gelen sıcaklığın değişimi 0 ile $0.16 \mu$ s aralığında zamana bağlı olarak verilmiştir. Buradan görüleceği gibi malzeme yüzey sıcaklığı, ergime sıcaklığına kısa sürede ulaşmaktadır. Ergime sıcaklığında kısa bir süre sabit sıcaklıkta devam etmekte ve ergime tamamlandiktan sonra sıvı fazdaki sıcaklık artışı devem etmektedir. Darbeli laser $1.10^{10} \mathrm{~W} / \mathrm{m}^{2}$ güç yoğunluğunda; Çelik $0.014 \mu$ sn, Nikel $0.0174 \mu$ sn, Tantal 0.0224 $\mu$ sn ve Titanyum $0.0149 \mu$ sn sonra ergime sıcaklığına ulaştığı görülmektedir. Ergime sıcaklığına ulaşma süreleri malzemenin fiziksel özelliklerine (ergime sıcaklığı, özgül 1s1s1, 1sıl iletkenlik ve soğurma katsayıs1 vb.) bağlı olarak değişmektedir. Darbeli Laser $5.0^{10} \mathrm{~W} / \mathrm{m}^{2}$ güç yoğunluğunda, Çelik 0.0028 $\mu \mathrm{sn}$, Nikel $0.0035 \mu \mathrm{sn}$, Tantal $0.00448 \mu \mathrm{sn}$ ve Titanyum $0.00299 \mu$ sn sonra ergime sıcaklığına ulaşmaktadır. $\mathrm{Bu}$ sonuçların 
literatürle uyumlu olduğu görülmektedir [Yılbaş, 1986; Yılbaş ve Şahin, 1993].

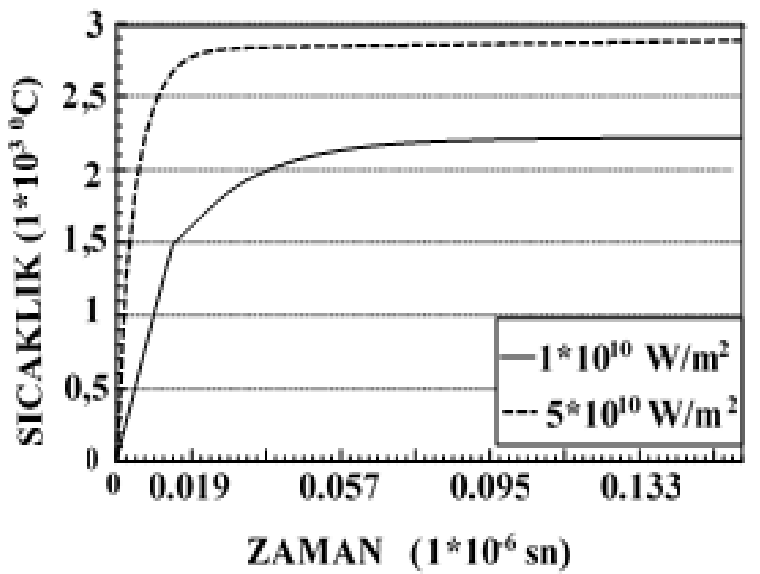

Çelik

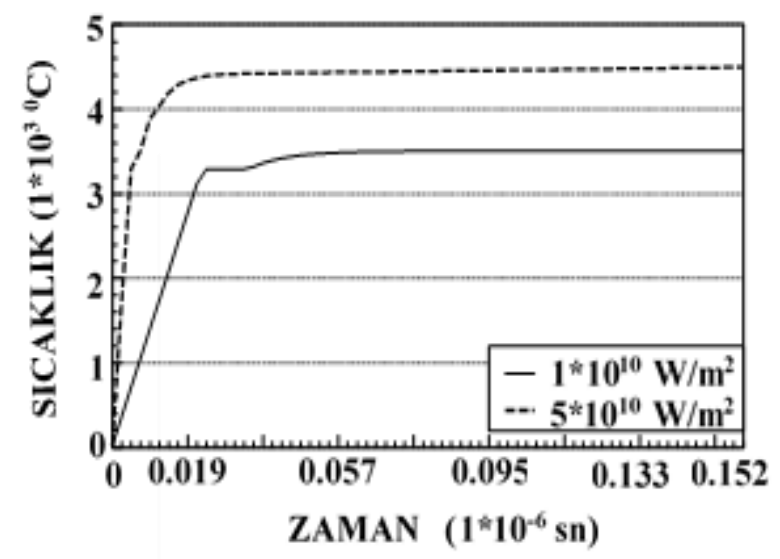

Tantalum

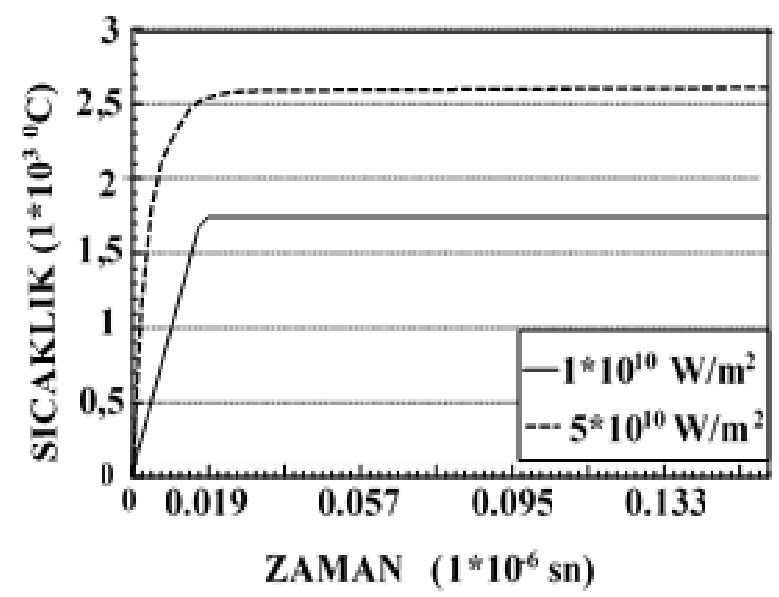

Nikel

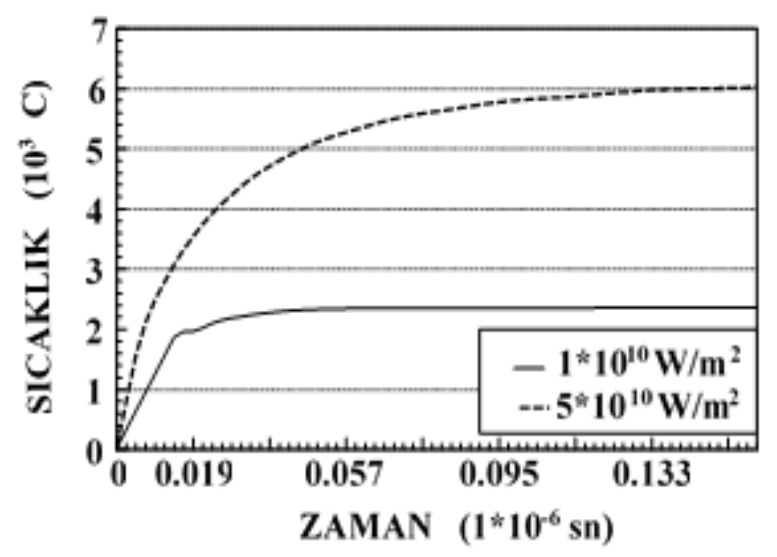

Titanium

Şekil 4. Darbeli laser $1.10^{10} \mathrm{~W} / \mathrm{m}^{2}$ güç yoğunundaki laser 1 şını ile etkileşimi malzeme içerisindeki sıcaklık dağılımlarının malzeme derinliğine göre değişimi.

Darbeli laser $1.10^{10} \mathrm{~W} / \mathrm{m}^{2}$ güç etmektedir. Yarı klasik teori yaklaşımında, yoğunluğundaki, laser ışını ile sırasıyla sıvı fazda yüzeyden malzeme içerisine doğru Çelik, Nikel, Tantal ve Titanyum olan sıcaklıktaki azalma hızlı bir şekilde malzemelerinin etkileşimi sırasında değişik meydana gelmektedir. Bunun nedeni ise yarı zamanlarda, malzeme yüzeyine dik klasik teoride taşınımla olan 1sı transferinin doğrultudaki yarı klasik teori yaklaşımına klasik yaklaşımla yapılması ve yüksek güç göre sıcaklık dağılımları verilmiştir. Yarı yoğunluklarında hataların büyümesinden ileri klasik teori yaklaşımında malzemenin gelmektedir. $5.10^{10} \mathrm{~W} / \mathrm{m}^{2}$ güç yoğunundaki derinliğine doğru sıvı fazda sıcaklık laser ışını ile etkileşimi malzeme içerisindeki exponansiyel olarak hızlı bir düşüş sıcaklık dağılımlarının malzeme derinliğine göstermekte, faz değiştirme sıcaklığında sabit kalmakta ve daha sonra yine exponansiyel göre değişimi Şekil 5'de verilmiştir.

olarak azalarak asimtot olarak devam 


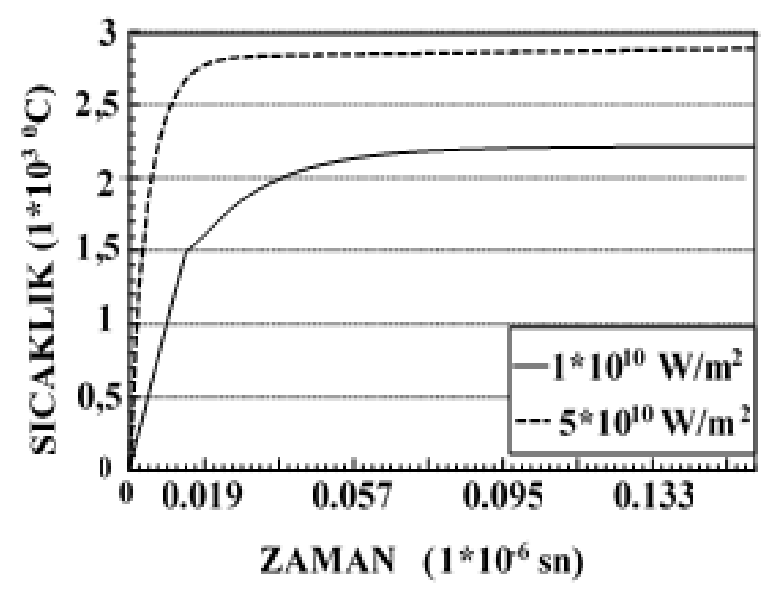

Çelik

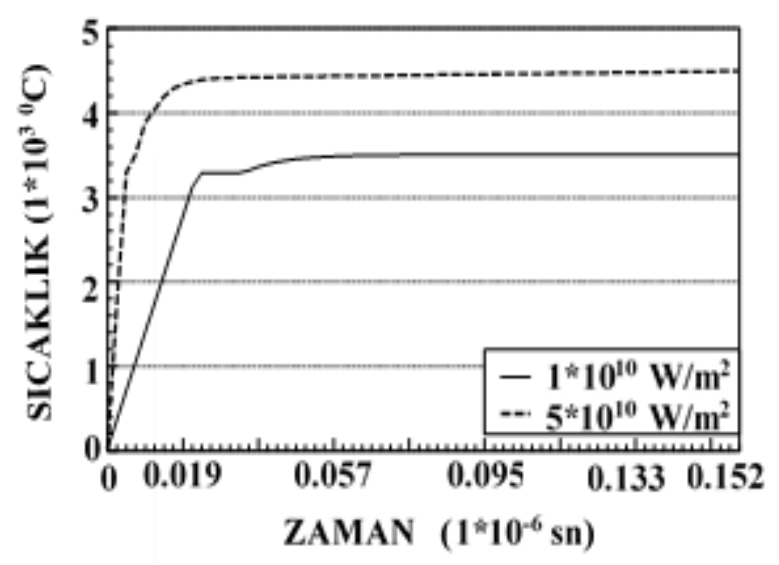

Tantalum

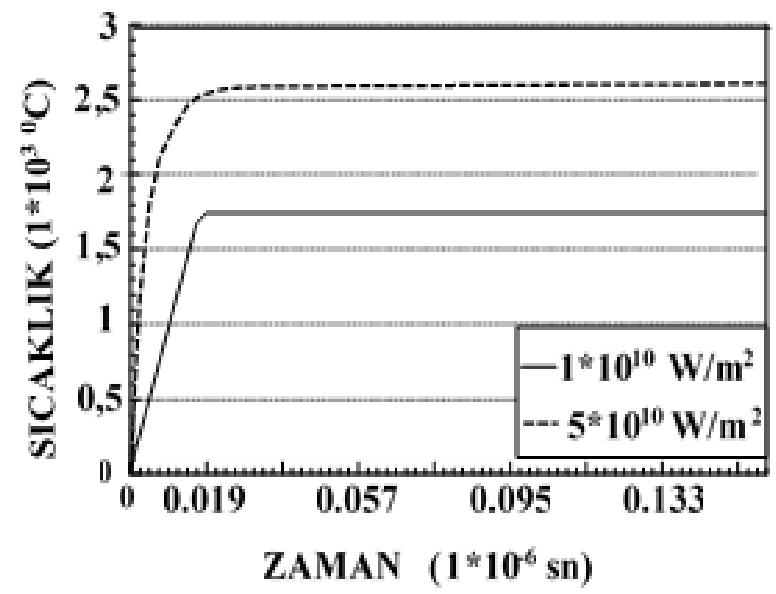

Nikel

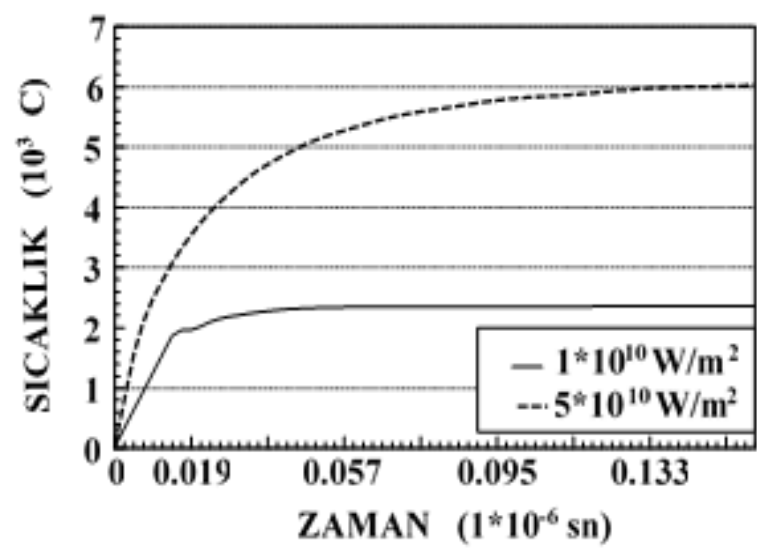

Titanium

Şekil 5. Darbeli laser $5.10^{10} \mathrm{~W} / \mathrm{m}^{2}$ güç yoğunundaki laser 1 şını ile etkileşimi malzeme içerisindeki sıcaklık dağılımlarının malzeme derinliğine göre değişimi

Darbeli laser $5.10^{10} \quad \mathrm{~W} / \mathrm{m}^{2}$ güç sıcaklık farkı çok büyümektedir. $\mathrm{Bu}$ da yoğunluğundaki, laser ışını ile sırasıyla malzemenin fiziksel özellikleri aynı Çelik, Nikel, Tantal ve Titanyum olduğundan malzeme derinliğine olan 1s1 malzemelerinin etkileşimi sırasında değişik transfer hızı yüzeydeki sıcaklık artışından zamanlarda, malzeme yüzeyine dik daha yavaşolmaktadır.

doğrultudaki yarı klasik teori yaklaşımına göre sıcaklık dağılımları verilmiştir. Malzeme yüzeyindeki sıcaklık artışı Şekil 3.2 de verilen $1.10^{10} \mathrm{~W} / \mathrm{m}^{2}$ güç yoğunluğundaki laser malzeme etkileşimiyle karşılaştığında, sıcaklık dağılımları benzer bir eğilim izlemesine rağmen, yüzeydeki sıcaklık artışı çok hızlı olmaktadır. Buna karşılık malzeme $\mathrm{Bu}$ çalışmada geliştirilen bilgisayar programı ile 8 elektron serbest aralığına eşit derinlik incelenebilmiştir. $\mathrm{Bu}$ aralıktan daha büyük derinlikler için bilgisayar işlem zamanının çok uzun olması ve nümerik analizden doğan yuvarlama hatalarının büyümesi nedeni ile analiz yapılamamıştır. yüzeyine dik ve malzeme derinliğindeki 


\section{Sonuç ve Tartışma}

$\mathrm{Bu}$ çalışmada, yarı klasik teori yaklaşımı ile elde edilen sonuçlar şu şekilde sıralanabilir. Malzeme yüzeyine dik doğrultuda, artan malzeme derinliğine doğru sıcaklık değişimi sıv1 faz bölgesine kadar önce exponansiyel bir şekilde düşüş gösterir. Ergime sıcaklığında ise sıcaklık sabit kalmaktadır. Daha sonra katı faz içerisinde malzeme derinliği arttıkça sıcaklık, hızlı bir şekilde exponansiyel olarak azalma göstermekte ve daha sonra asimtot olarak devam etmektedir. Yapılan analiz sonucunda yüzey sıcaklı̆̆ arttıkça malzeme içerisindeki faz değiştirme bölgesi gittikçe küçülmektedir.

Malzeme yüzeyinde zamana bağlı olarak sıcaklık artışları göz önüne alındığında, yapılan analiz sonucu üç bölge göz önüne alınabilir. Birinci bölge katı faz bölgesi olup sıcaklık artışı grafiklerde lineer görünmesine rağmen çok azda olsa parabolik olarak ergime noktasına kadar devam etmektedir. İkinci bölge sıvı faz bölgesi olup düşük yoğunluklardaki enerjilerde sicaklık, ilk önce sabit kalmakta ve daha sonra yavaş yavaş artmaktadır. $\mathrm{Bu}$ durum verilen enerjinin elektron ve atomların kinetik enerji artışının duraklayarak ve potansiyel enerjilerinin artması yani faz değişimleri için gerekli olan gizli 1sıya dönüştüğü şeklinde açıklanabilir. Ancak yüksek yoğunluklardaki laser 1şını ile malzeme temas halinde olduğunda faz değişimi daha kısa bir zaman içerisinde meydana gelmektedir. Üçüncü bölgede ise buharlaşma sıcaklığının üzerinde yüzey sıcaklığı daha hızlı olarak artmaktadır.

Yüzeydeki sıcaklık artışı zamana bağlı olarak incelendiğinde; 1sı iletim katsayısı küçülk Kðe, soğurma katsayısı büyük olan malzemelerde yüzeydeki sıcaklık artışının daha hızlı olduğu tespit edilmiştir. Buna karşılık 1sı iletim katsayısı büyük olan malzemelerde yüzeydeki sıcaklık artışı yavaş olmakta ve malzeme derinliğine doğru sıcaklık artış1 daha hızlı olmaktadır.

\section{Kaynaklar}

Beck, R. J., Parry, J. P., MacPherson, W. N., Waddie, A., Weston, N. J., Shephard, J. D., \& Hand, D. P. (2010). "Application of cooled spatial light modulator for high power nanosecond laser micromachining", Optics express,18(16), 17059-17065.

Belforte, D., \& Levitt, M. (Eds.). (2012)."The industrial laser handbook": Edition. Springer Science \& Business Media. 1992-1993

Bulgan, A.T., Koç, A., Keçeciler, A., (1991) "The Heat Transfer Analysis Which Happens During Laser-Metal Interaction", J. Inst Sci.Techno Gazi Univ, Vol.:4, No:1, pp:1537, January 1991].

Dekker, A. J. (1958). "Solid State Physics", Vol. 6.Seitz and D. Turnbull, eds., Academic Press, New York, 251.

Dekker, A. J. (1981). "In Solid State Physics", Chapter 16, page no 408, Pub.

Joe, D. J., Kim, S., Park, J. H., Park, D. Y., Lee, H. E., Im, T. H., ... \& Lee, K. J. (2017). "Laser-material interactions for flexible applications",Advanced Materials,29(26), 1606586.

Kittel, C. (2005). "Introduction to solid state physics", John Wiley \& Sons.Inc., New York. Koc, A., Yilbas, B. S., Koc, Y., Said, S., Gbadebo, S. A., \& Sami, M. (1998)."Material response to laser pulse heating: a kinetic theory approach",.Optics and lasers in engineering,30(3-4), 327-350.

A. (2004). "3-D analysis of temperature distribution in the material during pulsed laser and material interaction". Heat and mass transfer, 40(9), 697-706. 
Koc Y. (1995). "Kinetik teori yaklaşımı ile lase-malzeme etkileşimi sırasında malzemedeki sıcaklık dağılımının analizi”. Yüksek lisans tezi. Erciyes Üniversitesi Fenbilimleri Enstitüsü., Kayseri,1995

Koç, A., Yağlı, H., Koç, Y., \& Uğurlu, İ. (2018). Dünyada ve Türkiye'de Enerji Görünümünün

Değerlendirilmesi. Engineer \& the

Machinery Magazine, 59(692).

Maiman, T. H. (1960). "Stimulated optical radiation in ruby. Masers", Nature, 187,484$.493,1960]$.

Merhav, N. (2018). "Vibrations in a SolidPhonons and Heat Capacity $\$ \$^{\wedge *} \$ \$$. In" Statistical Physics for Electrical Engineering (pp. 95-102). Springer, Cham.

Neto, O. D., \& Lima, C. A. S. (1994). "Nonlinear three-dimensional temperature profiles in pulsed laser heated solids", Journal of Physics D: Applied Physics, 27(9), 1795.

Remo, J. L., \& Adams, R. G. (2008, May). "High energy density laser interactions with planetary and astrophysical materials: methodology and data. In", High-Power Laser Ablation VII , (Vol. 7005, p. 70052M). International Society for Optics and Photonics.

Prokhorov, A. M., Konov, V. I., Ursu, I., \& Mihailescu, I. N. (1990). "Laser Heating of Metals", Adam Hilger Series on Optics and Optoelectronics, Bristol: Hilger.

Qiu, T. Q., \& Tien, C. L. (1992). "Shortpulse laser heating on metals", International Journal of Heat and Mass Transfer, 35(3), 719-726.

Simon, G., Gratzke, U., \& Kroos, J. (1993). "Analysis of heat conduction in deep penetration welding with a time-modulated laser beam", Journal of Physics D: Applied Physics, 26(5), 862.
Townes, C. H., \& Schawlow, A. L. (1958). "Infrared and optical Masers", Phys. Rev, 112(6), 1940-1949.

Yan, J., Zhang, Y., Kim, P., \& Pinczuk, A. (2007). "Electric field effect tuning of electron-phonon coupling in graphene", Physical review letters, 98(16), 166802.

Yilbas, B. S. (1986). "Heating of metals at a free surface by laser irradiation-an electron kinetic theory approach", Laser and Particle Beams, 4(2), 275-286.

Yilbas, B. S., \& KOÇ, A. (1986), "Nd+ 3 Laser Rodunda Is1l Gerilmelerin ve Optik Distorsiyonların İncelenmesi", Erciyes Üniversitesi Fen Bilimleri Enstitüsü Fen Bilimleri Dergisi, 2109-119.

Yilbas, B. S., \& Apalak, K. (1987). "The basic concepts of heat transfer mechanism during laser drilling of metals", Egypt J. of Phys, 18(2), 133-156.

Yilbaş, B. S., \& Yilbaş, Z. (1988). "Some aspects of laser-metal vapour interaction", Pramana, 31(5), 365-381.

Yilbas, B. S., Davies, R., Yilbas, Z., \& Koc, A. (1990). Analysis of the absorption mechanism during laser-metal interaction. Pramana, 34(6), 473-489.

Yilbaş, B. S. (1993). "Analytical solution for the heat conduction mechanism appropriate to the laser heating process", International communications in heat and mass transfer, 20(4), 545-555.

Yilbaş, B. S., \& Şahin, A. Z. (1993). "An approach to convergency of kinetic theory to Fourier theory in relation to laser heating process", Japanese journal of applied physics, 32(12R), 5646

Yilbas, B. S., \& Sami, M. (1995). "Laser heating mechanisms including evaporation process-semiclassical and kinetic theory 
approaches", Japanese journal of applied physics, 34(12R), 6391.

Yilbas, B. S. (1997). "Laser heating process and experimental validation", International journal of heat and mass transfer, 40(5), 1131-1143.
Yilbas, B. S., \& Kalyon, M. (2002). "Analytical solution for pulsed laser heating process: convective boundary condition case", International journal of heat and mass transfer, 45(7), 1571-1582. 